Article

\title{
A Multiplex RT-PCR Assay to Detect and Discriminate Porcine Reproductive and Respiratory Syndrome Viruses in Clinical Specimens
}

\author{
Keli Yang *, Yongxiang Tian *, Danna Zhou, Zhengying Duan, Rui Guo, Zewen Liu, \\ Fangyan Yuan and Wei Liu
}

Key Laboratory of Prevention and Control Agents for Animal Bacteriosis (Ministry of Agriculture), Institute of Animal Husbandry and Veterinary, Hubei Academy of Agricultural Sciences, Wuhan 430064, China; zdn_66@126.com (D.Z.); zy001d@sina.com (Z.D.); hlguorui@163.com (R.G.); liuzwen2004@sina.com (Z.L.); hbxms@126.com (F.Y.); liuwei85@126.com (W.L.)

* Correspondence: keliy6@126.com (K.Y.); tyxanbit@163.com (Y.T.); Tel.: +86-27-8738-0860 (K.Y.)

Academic Editor: Curt Hagedorn

Received: 15 May 2017; Accepted: 28 July 2017; Published: 1 August 2017

\begin{abstract}
Outbreaks of highly pathogenic porcine reproductive and respiratory syndrome virus (HP-PRRSV) have led to large economic losses in China. The attenuated vaccine (HP-PRRSV JXA1-R) was used to control HP-PRRSV. However, in recent years, co-infection with classical PRRSV (C-PRRSV), HP-PRRSV, and/or HP-PRRSV JXA1-R has been increasing in China, resulting in a significant impact on PRRSV diagnostics and management. To facilitate rapid discrimination of HP-PRRSV JXA1-R from HP-PRRSV and C-PRRSV, a multiplex RT-PCR assay for the visual detection of HP-PRRSV JXA1-R, HP-PRRSV, and C-PRRSV was established and evaluated with reference PRRSV strains and clinical samples. Primer specificities were evaluated with RNA/DNA extracted from 10 viral strains, and our results revealed that the primers had a high specificity for PRRSV. The assay sensitivity was 24 copies $/ \mu \mathrm{L}$ for PRRSVs. A total of 516 serum samples were identified, of which $12.21 \%(63 / 516)$ were HP-PRRSV-positive, 2.33\% (12/516) were HP-PRRSV JXA1-R-positive, and $1.16 \%(6 / 516)$ were C-PRRSV-positive, respectively, which was completely consistent with the sequencing method. The high specificity, sensitivity, and reliability of the multiplex RT-PCR assay described in this study indicate that it is useful for the rapid and differential diagnosis of HP-PRRSV JXA1-R, HP-PRRSV, and C-PRRSV.
\end{abstract}

Keywords: porcine reproductive and respiratory syndrome virus; highly pathogenic; vaccine strain; multiplex RT-PCR; viral discrimination

\section{Introduction}

Porcine reproductive and respiratory syndrome (PRRS) is one of the most economically important swine diseases worldwide. The etiological agent of PRRS is the porcine reproductive and respiratory syndrome virus (PRRSV) which belongs to the order Nidovirales, family Arteriviridae [1]. PRRSV can be divided into European genotype (type 1) and North American genotype (type 2) with Lelystad and VR-2332 as prototypical strains, respectively [2]. The viruses under two genotypes could be further divided into different sub-genotypes according to virus genome characteristics based on phylogenetic analysis [3]. PRRSV was first confirmed in China in 1996 [4], and since then the virus has been found throughout China [5,6]. In May 2006, HP-PRRSV (a highly pathogenic form of PRRSV) severely impacted the pig industry in South China, which led to the death of more than 2 million pigs [7]. Classical PRRSV (C-PRRSV) is the prototypical strain of North American (type 2) genotype VR-2332. The C-PRRSV, HP-PRRSV, and HP-PRRSV JXA1-R strains all belongs to the North 
American (type 2) genotype, and the PRRSV strains circulating in China are almost all of the North American (type 2) genotype [8,9]. Despite the development and application of modified live vaccines for HP-PRRSV, the virulent HP-PRRSV variants were constantly reported under the massive national immunization campaign [2]. In recent years, co-infection with classical PRRSV (C-PRRSV), HP-PRRSV, and/or HP-PRRSV JXA1-R has been increasing in China, resulting in a significant impact on PRRSV diagnostics and management. Isolation of the pathogenic agents and/or differential serological tests were used for identification and differentiation of PRRSV. However, they are labor-intensive and time-consuming procedures. Molecular typing methods have been developed, and are currently used for rapid detection and identification of PRRSV [10]. Recently, a multiplex real-time RT-PCR based on specific probes was developed for type 1, type 2, and HP-PRRSVs [10]; a SYBR-green-based real-time RT-PCR assay has been developed for detection and differentiation of HP-PRRSV and C-PRRSV [11]; and a one-step RT-PCR assay has been developed for the detection and differentiation of HP-PRRSV and C-PRRSV [12]. However, these assays are not suitable for the differentiation of C-PRRSV, HP-PRRSV, and HP-PRRSV JXA1-R strains. Prompt detection and discrimination of PRRSV in field samples are important for effective PRRS control, thereby reducing the potentially serious economic losses from an outbreak. Therefore, a rapid, convenient, sensitive, and specific diagnostic method to discriminate between C-PRRSV, HP-PRRSV, and HP-PRRSV JXA1-R strains would be extremely useful for the diagnosis and control of PRRSV in China.

In this study, a multiplex RT-PCR assay was developed for the detection and discrimination of C-PRRSV, HP-PRRSV, and HP-PRRSV JXA1-R strains. The proposed method was shown to be a convenient, sensitive, reliable, and suitable tool to aid the prevention and control of PRRS.

\section{Materials and Methods}

\subsection{Viruses, Cells, and Reagents}

C-PRRSV strain CH-1a (GenBank ID: AY032626) is the first wild-type strain isolated from China, and was kindly provided by Hanzhong Wang (Wuhan Institute of Virology, Chinese Academy of Sciences, Wuhan, China). PRRSV strain 07HBEZ is a highly pathogenic North American-type PRRSV, and was isolated in 2007 (GenBank ID: FJ495082.2). HP-PRRSV JXA1-R strain was isolated from highly pathogenic porcine reproductive and respiratory syndrome vaccine, live (JXA1-R) (Pulike Biological Engineering Inc., Luoyang, China).

Marc-145 cells were cultured and maintained in DMEM supplemented with 10\% newborn calf serum (Gibco) at $37{ }^{\circ} \mathrm{C}$ in a humidified $5 \% \mathrm{CO}_{2}$ incubator. Other viruses, including classical swine fever virus (CSFV), pseudorabies virus (PRV), porcine circovirus type 2 (PCV2), porcine parvovirus (PPV), Japanese encephalitis virus (JEV), rotavirus (RV), porcine epidemic diarrhea virus (PEDV), stored in our laboratory, were used to confirm the specificity of the proposed multiplex RT-PCR assay.

\subsection{Clinical Specimen Collection}

A total of 516 serum samples were obtained from 10 pig farms in Hubei Province, central China, from June to August 2016. All samples used in this study were collected in accordance with international standards for animal welfare.

The pigs were immunized with live vaccine of HP-PRRSV JXA1-R strain (Pulike Biological Engineering Inc.) according to the manufacturer's instructions at about 30 days old. The serum samples were collected from the pigs when they were about 50 days old. Before samples were collected, there were no clinical signs of PRRSV in the farms.

\subsection{Primers Design}

The primers were designed using Primer Premier 5.0 (Primer Biosoft International, Palo Alto, Santa Clara, CA, USA) based on the PRRSV sequences in GenBank database to amplify the discontinuous 30-aa deletion in the NSP2 gene between HP-PRRSV and C-PRRSV genome sequences, and the 
nucleotide fragments $(13,380-13,900 \mathrm{nt})$ of HP-PRRSV and HP-PRRSV JXA1-R strain, respectively (Table 1). The specificity of the primers was confirmed against random nucleotide sequences obtained by a BLAST search in the GenBank database. The PCR-amplified HP-PRRSV and C-PRRSV products were 229 and $319 \mathrm{bp}$, respectively, and the PCR-amplified products of HP-PRRSV JXA1-R strain were two bands of $229 \mathrm{bp}$ and $620 \mathrm{bp}$.The primers were synthesized by Sangon Biotech Co., Ltd. (Shanghai, China).

Table 1. The primer sequences for multiplex RT-PCR.

\begin{tabular}{|c|c|c|c|c|c|}
\hline Primer & Primer Sequences $\left(5^{\prime}-3^{\prime}\right)$ & Origin/Target Gene & Location & Products & Source \\
\hline Nsp2-F & TGAYGGGCGACAATGTCC & $\begin{array}{c}\text { PRRSV CH-1a } \\
\text { (GenBank:AY032626)/Nsp2 }\end{array}$ & $\begin{array}{l}\text { 2745-2762(AY032626) } \\
\text { 1406-1423(FJ495082.2) }\end{array}$ & $\begin{array}{c}319 \mathrm{bp} \\
\text { (AY032626) }\end{array}$ & \multirow{2}{*}{$\begin{array}{l}\text { Previous } \\
\text { study [12] }\end{array}$} \\
\hline Nsp2-R & CGCAGACAAATCCAGAVG & $\begin{array}{c}\text { PRRSV 07HBEZ } \\
\text { (GenBank:FJ495082.2)/Nsp2 }\end{array}$ & $\begin{array}{l}\text { 3064-3047(AY032626) } \\
\text { 1635-1618(FJ495082.2) }\end{array}$ & $\begin{array}{c}229 \mathrm{bp} \\
\text { (FJ495082.2) }\end{array}$ & \\
\hline JXA1-F & ATTTGAATGTTCGCACGGTCTC & $\begin{array}{c}\text { PRRSV 07HBEZ } \\
\text { (GenBank:FJ495082.2)/GP4 }\end{array}$ & $13,380-13,401$ & $\begin{array}{c}\text { None } \\
\text { (FJ495082.2) }\end{array}$ & \multirow[t]{2}{*}{$\begin{array}{l}\text { This } \\
\text { study }\end{array}$} \\
\hline JXA1-R & CCGCTGAAACTCTGGTTAAAGG & $\begin{array}{c}\text { PRRSV JXA1-P170 } \\
\text { (GenBank:JQ804986.1)/GP5 }\end{array}$ & $13,879-13,900$ & $\begin{array}{c}620 \mathrm{bp} \\
(J Q 804986.1)\end{array}$ & \\
\hline
\end{tabular}

\subsection{Nucleic Acid Extractions}

Viral RNA samples for multiplex RT-PCR were extracted from the serum samples using the TaKaRa MiniBEST Viral RNA Extraction Kit Ver.4.0 (TaKaRa, Dalian, China) according to the manufacturer's protocol. Total RNA was eluted with $40 \mu \mathrm{L}$ of diethylpyrocarbonate-treated water and stored at $-80^{\circ} \mathrm{C}$ until use.

Viral genomic RNA or DNA to test the specificity of the multiplex RT-PCR assay were extracted from cell cultures infected by each virus using the TaKaRa MiniBEST Viral RNA/DNA Extraction Kit Ver. 4.0 (TaKaRa, Dalian, China) according to the manufacturer's instructions.

\subsection{First Strand cDNA Synthesis}

First strand cDNA was synthesized from $5 \mu \mathrm{g}$ total RNA using PrimeScript ${ }^{\mathrm{TM}} 1$ st Strand cDNA Synthesis Kit (TaKaRa) following the manufacturer's protocol with OligodT primer.

\subsection{Single PCR and Plasmid Template Construction}

The PCR reaction was conducted in a $25 \mu \mathrm{L}$ mixture including $2.5 \mu \mathrm{L} 10 \times$ PCR buffer, $2 \mu \mathrm{L}$ $10 \mathrm{mM}$ of each dNTPs, $0.5 \mu \mathrm{L}$ of each $10 \mu \mathrm{M}$ primer (Table 1$), 1.25 \mathrm{U}$ of Taq DNA polymerase $(5 \mathrm{U} / \mu \mathrm{L}$ ) (TaKaRa), $2.5 \mu \mathrm{L}$ of the cDNA, and distilled water was added to $25 \mu \mathrm{L}$.

The amplifications were performed in a thermal cycler (Bio-Rad, Hercules, CA, USA) under the following conditions: after initial denaturation at $95^{\circ} \mathrm{C}$ for $5 \mathrm{~min}, 35$ cycles were conducted at $95{ }^{\circ} \mathrm{C}$ for $30 \mathrm{~s}, 58{ }^{\circ} \mathrm{C}$ for $45 \mathrm{~s}$, and $72{ }^{\circ} \mathrm{C}$ for $45 \mathrm{~s}$, followed by a final extension at $72{ }^{\circ} \mathrm{C}$ for $10 \mathrm{~min}$. The PCR products were detected by electrophoresing through $1.0 \%$ agarose gel in $1 \times$ TAE $(40 \mathrm{mM}$ Tris-aceate, $1 \mathrm{mM}$ EDTA, pH8.0). Each specific viral target fragment was cloned into the plasmid pMD18-T (TaKaRa). The constructed recombinant plasmids were sequenced and confirmed to use as standard templates for optimization of the following PCR assays.

\subsection{Optimization of the MultiplexRT-PCR Assay}

Based on the established single PCR, the multiplex RT-PCR was optimized by varying single parameters while other parameters were maintained. The evaluated parameters and ranges in concentrations included: primers, $2-30 \mathrm{pM}$; dNTPs, $100-400 \mu \mathrm{M}$, and TaKaRaTaq DNA polymerase, $0.5-2.5 \mathrm{U}$. The effects of annealing temperature (range: $55-62{ }^{\circ} \mathrm{C}$ ) and number of cycles (range: $25-35$ cycles) were also determined experimentally. The PCR products were detected by electrophoresing as described above. Negative control using distilled water instead of template cDNA was run with the test. 


\subsection{Specificity of the Proposed Multiplex RT-PCR Assay}

Specificity of the multiplex RT-PCR assay was determined by analyzing 10 different viral strains and $\mathrm{ddH}_{2} \mathrm{O}$ as negative control. C-PRRSV, HP-PRRSV, and HP-PRRSV JXA1-R strains were identified by sequencing, and the other virus strains (CSFV, PRV, PCV2, PPV, JEV, RV, and PEDV) were verified by serological or PCR methods. Viral RNA extracted from C-PRRSV-, HP-PRRSV-, and HP-PRRSV JXA1-R infected cell supernatants with approximate viral titers of $10^{3} \mathrm{TCID}_{50} / \mathrm{mL}$ were analyzed with the multiplex RT-PCR assay as described above.

\subsection{Sensitivity of the Proposed Multiplex RT-PCR Assay}

To assess the sensitivity of the proposed assay, the C-PRRSV, HP-PRRSV, and HP-PRRSV JXA1-R strains were determined in Marc-145 cells grown in 96-well plates, and the TCID 50 was calculated using the method of Reed and Muench [13].

Total RNA from the virus samples was extracted and analyzed with the sensitivity of the proposed multiplex RT-PCR assay. The RNA concentration was determined by spectrophotometry, and the exact number of RNA molecules was calculated. Then 10-fold serial dilution was performed from $2.4 \times 10^{5}$ copies $/ \mu \mathrm{L}$ to $2.4 \times 10^{-1}$ copies $/ \mu \mathrm{L}$ and used as templates for multiplex RT-PCR. The lowest amount of RNA detectable under the conditions described above was defined as the sensitivity of the multiplex RT-PCR assay.

\subsection{Detection of PRRSV in Clinical Specimens by the Multiplex PCR}

To evaluate the feasibility of multiplex RT-PCR detection of PRRSV, 516 clinical specimens described above were analyzed using the multiplex RT-PCR assay. To verify the accuracy of the developed protocol, all of the RT-PCR products from positive samples were cloned into the plasmid pMD18-T and sequenced by Sangon Biotech Co., Ltd (Shanghai, China). All of the negative samples were further detected using the one-step RT-PCR in our previous study [12].

\section{Results}

\subsection{MultiplexRT-PCR Assay Conditions}

The optimal parameters of multiplex RT-PCR assay were investigated. A final $25-\mu \mathrm{L}$ volume of the multiplex RT-PCR master mix contained of $2.5 \mu \mathrm{L}$ of $10 \times$ buffer, $0.25 \mu \mathrm{L}$ of Taq polymerase $(5 \mathrm{U} / \mu \mathrm{L}), 2.5 \mu \mathrm{L}$ of cDNA template, $2 \mu \mathrm{L}$ of dNTPs $(10 \mathrm{mM}), 0.5 \mu \mathrm{L}$ of forward and reverse primers $(10 \mu \mathrm{M})$, and $16.75 \mu \mathrm{L}$ nuclease-free water in each reaction tube. Master mixes were maintained on ice at all times prior to PCR analysis. An optimized experimental protocol on a Peltier Thermal Cycler machine (Bio-Rad, Hercules, CA, USA) consisted of a denaturation program $\left(95^{\circ} \mathrm{C}\right.$ for $5 \mathrm{~min}$ ) and an amplification program repeated 35 times (denaturation at $95^{\circ} \mathrm{C}$ for $30 \mathrm{~s}, 58^{\circ} \mathrm{C}$ for $40 \mathrm{~s}$, and elongation at $72^{\circ} \mathrm{C}$ for $45 \mathrm{~s}$ ), followed by a 10 -min extension at $72^{\circ} \mathrm{C}$.

HP-PRRSV JXA1-R cDNA, HP-PRRSV cDNA, C-PRRSV cDNA, and a negative control reaction mixture without template were analyzed using the above protocol, and the PCR amplification results are illustrated in Figure 1. 


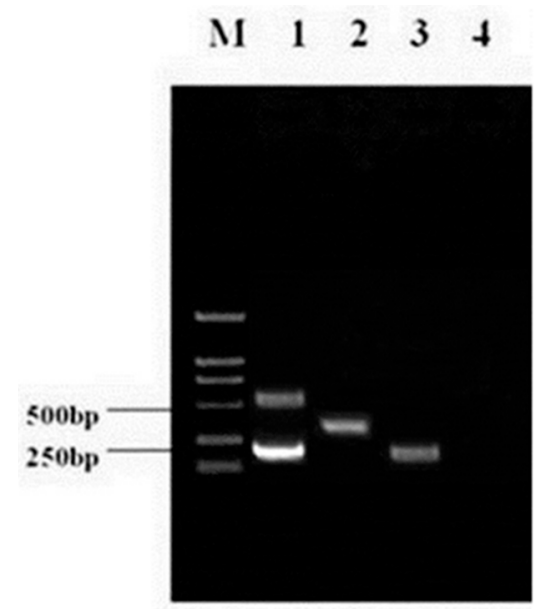

Figure 1. The results of multiplex RT-PCR in optimization conditions.Lane M, DL2000 DNA marker; lane 1, highly pathogenic porcine reproductive and respiratory syndrome virus (HP-PRRSV) strain JXA1-R; lane 2, classical PRRSV (C-PRRSV) strain CH-1a; lane 3, HP-PRRSV strain 07HBEZ; lane 4, $\mathrm{ddH}_{2} \mathrm{O}$.

\subsection{Specificity of the Proposed Multiplex RT-PCR Assay}

The specificity of the primer pairs for each virus was analyzed using the proposed multiplex RT-PCR assay. As illustrated in Figure 2, the multiplex RT-PCR assay was specific for the target virus because no amplification occurred with CSFV, PRV, PCV2, PPV, JEV, RV, PEDV, or $\mathrm{ddH}_{2} \mathrm{O}$ (lanes 4-11), whereas the HP-PRRSV JXA1-R, C-PRRSV, and HP-PRRSV target genes were specifically amplified using the defined primer pairs (lanes 1-3).

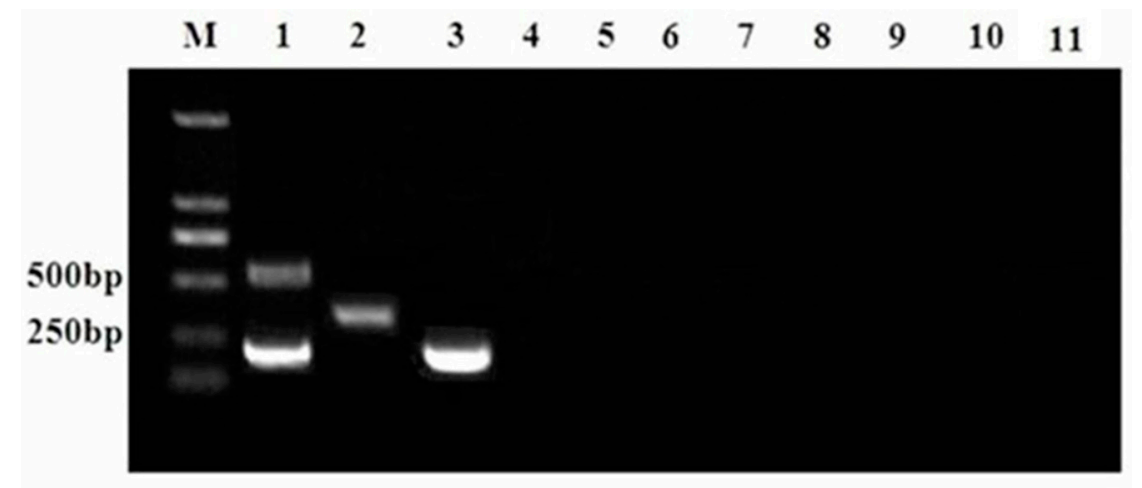

Figure 2. Specificity of multiplex RT-PCR. Lane M, DL2000 DNA marker; lane 1, HP-PRRSV JXA1-R; lane 2, C-PRRSV strain CH-1a; lane 3, HP-PRRSV strain 07HBEZ; lane 4, CSFV; lane 5, PRV; lane 6, PCV2; lane 7, PPV; lane 8, JEV; lane 9, RV; lane 10, PEDV; lane 11, $\mathrm{ddH}_{2} \mathrm{O}$.

\subsection{Sensitivity of Multiplex RT-PCR}

The sensitivity of the multiplex RT-PCR assay was defined as the minimum detectable RNA molecules concentration at which a positive amplification product could be detected.

Upon 10-fold serial dilution, RNA standards with known copy numbers $\left(2.4 \times 10^{5}\right.$ copies $/ \mu \mathrm{L}$ to $2.4 \times 10^{-1}$ copies $/ \mu \mathrm{L}$ ) were synthesized first strand cDNA and used for multiplex RT-PCR. As shown in Figure 3, multiplex RT-PCR successfully detected as little as 24 copies/ $\mu \mathrm{L}$ of RNA molecules, determined by the agarose gelelectrophoresis for the HP-PRRSV JXA1-R, C-PRRSV, and HP-PRRSV. The results demonstrated that the sensitivity of the multiplex RT-PCR was 24 copies / $\mu \mathrm{L}$ for HP-PRRSV JXA1-R, C-PRRSV, and HP-PRRSV. 


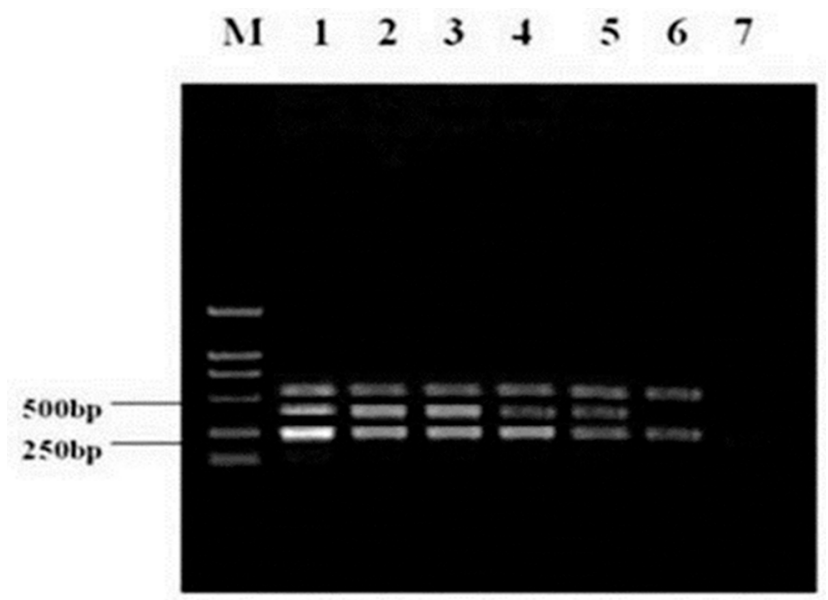

Figure 3. Sensitivity of multiplex RT-PCR for PRRSV Lane M, DL2000 DNA marker; lanes 1-7 are: $1,2.4 \times 10^{5} ; 2,2.4 \times 10^{4} ; 3,2.4 \times 10^{3} ; 4,2.4 \times 10^{2} ; 5,2.4 \times 10^{1} ; 6,2.4 \times 10^{0} ; 7,2.4 \times 10^{-1}$ copies $/ \mu \mathrm{L}$.

\subsection{Detection of Viruses in Clinical Specimens}

A total of 516 clinical specimens were tested by the multiplex RT-PCR assay with optimal parameters. The results were as follows: HP-PRRSV RNA was detected in 63 (12.21\%) of 516 serum samples, HP-PRRSV JXA1-R RNA was detected in 12 (2.33\%) of 516 serum samples, and C-PRRSV RNA was detected in $6(1.16 \%)$ of 516 serum samples, respectively, which were $100 \%$ correlated with the sequencing method (Table 2). The results of one-step RT-PCR for negative samples were same as those of the multiplex RT-PCR assay we developed. The results obtained by the multiplex RT-PCR method and subsequent sequencing further indicated the accuracy of the developed method.

Additionally, two HP-PRRSV JXA1-R and HP-PRRSV positive, one HP-PRRSV and C-PRRSV positive, and two HP-PRRSV JXA1-R and C-PRRSV positive clinical samples were detected in samples from four pig farms (Table 2). The rate of co-infection was $0.97 \%(5 / 516)$ in all of the detected clinical specimens.

Table 2. Detection rates of clinical specimens by multiplex RT-PCR and sequencing method.

\begin{tabular}{|c|c|c|c|c|c|c|c|c|}
\hline \multirow[b]{2}{*}{$\begin{array}{l}\text { Pig } \\
\text { Farm }\end{array}$} & \multirow[b]{2}{*}{$\begin{array}{c}\text { No. of } \\
\text { Specimens }\end{array}$} & \multicolumn{2}{|c|}{ Multiplex RT-PCR } & \multicolumn{5}{|c|}{ Sequencing Method } \\
\hline & & $\begin{array}{l}\text { HP-PRRSV JXA1-R } \\
\text { Positive (\%) }\end{array}$ & $\begin{array}{l}\text { HP-PRRSV } \\
\text { Positive (\%) }\end{array}$ & $\begin{array}{c}\text { C-PRRSV } \\
\text { Positive (\%) }\end{array}$ & $\begin{array}{l}\text { HP-PRRSV JXA1-R } \\
\text { Positive (\%) }\end{array}$ & $\begin{array}{l}\text { HP-PRRSV } \\
\text { Positive (\%) }\end{array}$ & $\begin{array}{c}\text { C-PRRSV } \\
\text { Positive (\%) }\end{array}$ & $\begin{array}{c}\text { Concordance } \\
\text { Rate }(\%)\end{array}$ \\
\hline 1 & 56 & $1(1.79)$ & $6(10.71)$ & $0(0)$ & $1(1.79)$ & $6(10.71)$ & $0(0)$ & 100 \\
\hline 3 & 45 & $1(2.22)$ & $5(11.11)$ & $0(0)$ & $1(2.22)$ & $5(11.11)$ & $0(0)$ & 100 \\
\hline 4 & 58 & $2^{a}(3.45)$ & $9^{\text {a }}(15.52)$ & $1(1.72)$ & $2^{\mathrm{a}}(3.45)$ & $9^{a}(15.52)$ & $1(1.72)$ & 100 \\
\hline 5 & 32 & $0(0)$ & $3(9.38)$ & $0(0)$ & $0(0)$ & $3(9.38)$ & $0(0)$ & 100 \\
\hline 8 & 57 & $2(3.51)$ & $6(10.53)$ & $0(0)$ & $2(3.51)$ & $6(10.53)$ & $0(0)$ & 100 \\
\hline 9 & 66 & $2^{c}(3.03)$ & $10(15.15)$ & $2^{c}(3.03)$ & $2^{c}(3.03)$ & $10(15.15)$ & $2^{c}(3.03)$ & 100 \\
\hline 10 & 58 & $1(1.72)$ & $6(10.34)$ & $0(0)$ & $1(1.72)$ & $6(10.34)$ & $0(0)$ & 100 \\
\hline Total & 516 & $12(2.33)$ & $63(12.21)$ & $6(1.16)$ & $12(2.33)$ & $63(12.21)$ & $6(1.16)$ & 100 \\
\hline
\end{tabular}

${ }^{a}$ One sample in the farm was HP-PRRSV JXA1-R and HP-PRRSV positive, the positive ratio was $1.67 \%(1 / 60)$ and $1.72 \%(1 / 58)$, respectively; ${ }^{b}$ One sample in the farm was HP-PRRSV and C-PRRSV positive, the positive ratio was $2.04 \%(1 / 49){ }^{c}$ Two samples in the farm were HP-PRRSV JXA1-R and C-PRRSV positive, the positive ratio was $3.03 \%(2 / 66)$

\section{Discussion}

PRRSV has obsessed the pig industry for decades and leads to massive economic losses all over the world. In 2006, a highly-pathogenic PRRSV occurred in China, affected over 2,000,000 pigs with about 400,000 fatal cases [7]. The outbreaks observed were further characterized by a rapid spread within the affected provinces, and it was observed that pigs of all ages were affected [14]. 
Due to its high rates of mutation and recombination events, the protection ability of PRRSV vaccines was compromised if infection froma heterologous virus occurred [15]. In order to prevent PRRS, six live attenuated PRRSV vaccines including PRRSMLV, CH-1R, and R98 for C-PRRSV, and JXA1-R, HuN4-F112, and TJM-F92 specific for HP-PRRSV are currently marketed in China [16], and the JXA1-R strain has been widely used in recent years. However, co-infection with classical PRRSV (C-PRRSV), HP-PRRSV, and/or HP-PRRSV JXA1-R has been increasing in China, resulting in a significant impact on PRRSV diagnostics and management.

PRRS diagnosis is typically accomplished by viral isolation followed by immunochromatochemical analysis, serological methods, and/or conventional RT-PCR. However, viral isolation is complex, labor intensive, and time-consuming. Immunochromatochemical and serological methods have low specificity and/or sensitivity [17]. To overcome these shortcomings and obtain more accurate diagnoses, real-time RT-PCR assays specific for the highly-pathogenic PRRSV have been developed [18-20], and some qRT-PCR assays and one-step RT-PCR assays have been developed for the detection and differentiation of HP-PRRSV and C-PRRSV [10-12]. These tests are highly specific and sensitive, but cannot distinguish C-PRRSV, HP-PRRSV, and HP-PRRSV JXA1-R strains coexisting in Chinese swine herds.

In the present study, we developed an efficient and sensitive multiplex RT-PCR assay for the detection and discrimination of C-PRRSV, HP-PRRSV, and HP-PRRSV JXA1-R strains using two specific primer pairs-one of which was designed in our previous study [12]. The PCR products produced from the specific primers are distinct for each PRRSV strain, and no amplification occurred with non-target viruses or $\mathrm{ddH}_{2} \mathrm{O}$, which can be visualized and easily differentiated by agarose gel electrophoresis checking. In addition, all the specific PCR products obtained by analyzing the clinical specimens were also cloned into pMD18-T and sequenced to further confirm the specificity of the multiplex assay. Generally, the presence of more than one pair of primers in the same reaction mix may limit the sensitivity or cause preferential amplification of specific targets [21], and the sensitivity of the multiplex PCR is usually approximately 10-fold lower than that of a single PCR [22]. Fortunately, the established multiplex RT-PCR assay in the study was as sensitive as the single PCR in our previous study [12] with a detection limit of 24 copies / $\mu$ L for PRRSV, which suggested a desired primer design and proper optimization of the multiplex RT-PCR assay developed. Moreover, the sensitivity was similar to that of a real-time RT-PCR-based assay for the same virus (the sensitivity of which was 20 copies $/ \mu L$ ) [10], and was higher than a multiplex PCR (the sensitivity of which was 800 copies/ $\mu \mathrm{L}$ ) [23] and a RT-qPCR assay (the sensitivity of which was 100 copies $/ \mu \mathrm{L}$ ) [24]. As we know, there are many factors that can affect the sensitivity of PCR assays, such as the nucleic acid extraction method, the cycles of PCR, and the PCR products detection method, etc. The sensitivity difference between the multiplex PCR we developed and the RT-qPCR assay [24] maybe caused by the factors above, and the sensitivity difference between the multiplex PCR we developed and another multiplex PCR assay [23] maybe mainly caused by the nucleic acid extraction method. In the present study, when assessing diagnostic performances, the sensitivity of the proposed multiplex RT-PCR assay was 24 copies $/ \mu \mathrm{L}$; that is to say, the samples with the virus below 24 copies / $\mu \mathrm{L}$ could not be detected as positive. Additionally, the sensitivity of the multiplex RT-PCR in this study, is similar with that of the one-step RT-PCR in our previous study [12], which was 25 copies / $\mu$ L for both HP-PRRSV and C-PRRSV. The difference between the two assays is that the one step RT-PCR assay can detect and discriminate HP-PRRSV and C-PRRSV, while the multiplex RT-PCR assay can detect and discriminate not only HP-PRRSV and C-PRRSV, but also HP-PRRSV JXA1-R. However, the PRRSV has genetic variability; when a new variant strain of PRRSV appears, it is possible that the multiplex RT-PCR would be unable to detect and discriminate it. This facet will also need further research.

In the present study, 516 specimens were detected using the multiplex RT-PCR, and the results were 100\% consistent with that of the sequencing method. In our clinical specimens, $12.21 \%(63 / 516)$ were HP-PRRSV-positive, 2.33\% (12/516) were HP-PRRSV JXA1-R-positive, and 1.16\% (6/516) were 
C-PRRSV-positive, respectively, which was completely consistent with that of the sequencing method. The results also indicated that the PRRSV infection was still severe in Hubei Province, Central China.

At present, several commercial PRRSV vaccines are used in pig farms in China, including modified live vaccines (MLV) and inactivated vaccines (IV). The use of vaccines in piglets has been more controversial, and is limited by the dynamics of viral circulation in the farm. When the flow of viremic piglets from maternities to nurseries is high, most piglets will be infected before the establishment of an active immunity due to vaccination [25]. Some studies have dealt with the evaluation of virus transmission to vaccinated and unvaccinated pigs [25-28]. Thus, in controlling PRRS, it is important to develop an assay to discriminate different PRRSV strains in clinical specimens.

Currently, the epidemic of atypical PRRS has not been completely controlled in China [14]. The highly pathogenic PRRSV may continue to impact the Chinese swine industry for an extended period [12]. PRRS is one of the most important pig diseases worldwide. The causative PRRSV is rapidly evolving and there is an urgent need for the development of quicker and more efficacious assay to discriminate PRRSV different strains to improve PRRS control.

Control of PRRSV infection in pig farms mainly relies on four pillars:biosecurity, diagnosis, herd management and immunization. Of these, diagnosisis essential to detect the pathogen and to limit the impact of the infection within an infected herd. Thus, we developed the proposed multiplex RT-PCR to aid in PRRS prevention and control. In this study, since we could discriminate PRRSV different strains in the clinical specimens, we believed that the multiplex RT-PCR could be used for the detection of PRRSV, and useful in implementing methods to prevent the transmission of the disease.

In summary, the proposed multiplex RT-PCR is a convenient, rapid, efficient, sensitive, and highly specific assay for the identification of different PRRSV strains. The size of amplified product is sufficient to distinguish the different PRRSV strains. Our method showed great promise not only in laboratory testing, but also in field and clinical applications. The simplicity and accuracy of the test make it a powerful tool for PRRSV detection and control in China.

Acknowledgments: The present study was supported by the National Key Research and Development Program of China (2016YFD0500703), Hubei Province Innovation Center of Agricultural Sciences and Technology (2016-620-000-001-026). It was also financed by the Key Natural Science Foundation of Hubei Province, China (2012FFA067) and the Opening Subject of Key laboratory of prevention and control agents for animal bacteriosis (Ministry of Agriculture) (2016ZD006).

Author Contributions: K.Y. and Y.T. conceived and designed the experiments; D.Z., Z.D. and Z.L. performed the experiments; F.Y. and W.L. analyzed the data; K.Y. wrote the paper; R.G. performed sampling, and provided the biological material. All the authors read and approved the final manuscript.

Conflicts of Interest: The authors declare that there was no conflict of interest in the preparation of this manuscript.

$\begin{array}{ll}\text { Abbreviations } \\ \text { PRRSV } & \text { porcine reproductive and respiratory syndrome virus } \\ \text { CSFV } & \text { classical swine fever virus } \\ \text { PRV } & \text { pseudorabies virus } \\ \text { PCV2 } & \text { porcine circovirus type } 2 \\ \text { PPV } & \text { porcine parvovirus } \\ \text { JEV } & \text { Japanese encephalitis virus } \\ \text { RV } & \text { rotavirus } \\ \text { PEDV } & \text { porcine epidemic diarrhea virus }\end{array}$

\section{References}

1. Renukaradhya, G.J.; Meng, X.J.; Calvert, J.G.; Roof, M.; Lager, K.M. Live porcine reproductive and respiratory syndrome virus vaccines: Current status and future direction. Vaccine 2015, 33, 4069-4080. [CrossRef] [PubMed]

2. Loving, C.L.; Osorio, F.A.; Murtaugh, M.P.; Zuckermann, F.A. Innate and adaptive immunity against porcine reproductive and respiratory syndrome virus. Vet. Immunol. Immunopathol. 2015, 167, 1-14. [CrossRef] [PubMed] 
3. Brar, M.S.; Shi, M.; Murtaugh, M.P.; Leung, F.C. Evolutionary diversification of type 2 porcine reproductive and respiratory syndrome virus. J. Gen. Virol. 2015, 96, 1570-1580. [CrossRef] [PubMed]

4. Guo, B.Q.; Chen, Z.S.; Liu, W.X.; Cui, Y.Z. Isolation and identification of porcine reproductive and respiratory syndrome (PRRS) virus from aborted fetuses suspected of PRRS. Chin. J. Anim. Pollut. Infect. Dis. 1996, 26, 1-5. (In Chinese)

5. Gao, Z.Q.; Guo, X.; Yang, H.C. Genomic characterization of two Chinese isolates of porcine respiratory and reproductive syndrome virus. Arch. Virol. 2004, 149, 1341-1351. [CrossRef] [PubMed]

6. Chen, J.; Liu, T.; Zhu, C.G.; Jin, Y.F.; Zhang, Y.Z. Genetic variation of Chinese PRRSV strains based on ORF5 sequence. Biochem. Genet. 2006, 44, 421-431. [CrossRef] [PubMed]

7. Tian, K.G.; Yu, X.L.; Zhao, T.Z.; Feng, Y.J.; Cao, Z.; Wang, C.B.; Hu, Y.; Chen, X.Z.; Hu, D.M.; Tian, X.S.; et al. Emergence of fatal PRRSV variants: Unparalleled outbreaks of atypical PRRS in China and molecular dissection of the unique hallmark. PLoS ONE 2007, 2, e526. [CrossRef] [PubMed]

8. Zhao, K.; Ye, C.; Chang, X.B.; Jiang, C.G.; Wang, S.J.; Cai, X.H.; Tong, G.Z.; Tian, Z.J.; Shi, M.; An, T.Q. Importation and recombination are responsible for the latest emergence of highly pathogenic porcine reproductive and respiratory syndrome virus in China. J. Virol. 2015, 89, 10712-10716. [CrossRef] [PubMed]

9. Zhou, Z.; Ni, J.; Cao, Z.; Han, X.; Xia, Y.; Zi, Z.; Ning, K.; Liu, Q.; Cai, L.; Qiu, P.; et al. The epidemic status and genetic diversity of 14 highly pathogenic porcine reproductive and respiratory syndrome virus (HP-PRRSV) isolates from China in 2009. Vet. Microbiol. 2011, 150, 257-269. [CrossRef] [PubMed]

10. Wernike, K.; Hoffmann, B.; Dauber, M.; Lange, E.; Schirrmeier, H.; Beer, M. Detection and typing of highly pathogenic porcine reproductive and respiratory syndrome virus by multiplex real-time RT-PCR. PLoS ONE 2012, 7, e38251. [CrossRef] [PubMed]

11. Chai, Z.; Ma, W.J.; Fu, F.; Lang, Y.K.; Wang, W.; Tong, G.Z.; Liu, Q.F.; Cai, X.H.; Li, X. A SYBR Green-based real-time RT-PCR assay for simple and rapid detection and differentiation of highly pathogenic and classical type 2 porcine reproductive and respiratory syndrome virus circulating in China. Arch. Virol. 2013, 158, 407-415. [CrossRef] [PubMed]

12. Yang, K.L.; Li, Y.H.; Duan, Z.Y.; Guo, R.; Liu, Z.W.; Zhou, D.N.; Yuan, F.Y.; Tian, Y.X. A one step RT-PCR assay to detect and discriminate porcine reproductive and respiratory syndrome viruses in clinical specimens. Gene 2013, 531, 199-204. [CrossRef] [PubMed]

13. Reed, L.J.; Muench, H. A simple method of estimating fifty percent end points. Am. J. Hyg. 1938, 27, 709-716.

14. Zhou, L.; Yang, H.C.; Lunney, J.K.; Rowland, R.R.R. Porcine reproductive and respiratory syndrome in China. Virus Res. 2010, 154, 31-37. [CrossRef] [PubMed]

15. Lunney, J.K.; Fang, Y.; Ladinig, A.; Chen, N.; Li, Y.; Rowland, B.; Renukaradhya, G.J. Porcine reproductive and respiratory syndrome virus (PRRSV): Pathogenesis and interaction with the immune system. Annu. Rev. Anim. Biosci. 2016, 4, 129-154. [CrossRef] [PubMed]

16. Yu, X.; Chen, N.; Wan, L.; Wu, J.; Zhou, Z.; Ni, J.; Li, X.; Zhai, X.; Shi, J.; Tian, K. New genomic characteristics of highly pathogenic porcine reproductive and respiratory syndrome viruses do not lead to significant changes in pathogenicity. Vet. Microbiol. 2012, 158, 291-299. [CrossRef] [PubMed]

17. Mengeling, W.L.; Lager, K.M. A brief review of procedures and potential problems associated with the diagnosis of porcine reproductive and respiratory syndrome. Vet. Res. 2000, 31, 61-69. [CrossRef] [PubMed]

18. Kleiboeker, S.B.; Schommer, S.K.; Lee, S.M.; Watkins, S.; Chittick, W.; Polson, D. Simultaneous detection of North American and European porcine reproductive and respiratory syndrome virus using real-time quantitative reverse transcriptase-PCR. J. Vet. Diagn. Investig. 2005, 17, 165-170. [CrossRef] [PubMed]

19. Lurchachaiwong, W.; Payungporn, S.; Srisatidnarakul, U.; Mungkundar, C.; Theamboonlers, A.; Poovorawan, Y. Rapid detection and strain identification of porcine reproductive and respiratory syndrome virus (PRRSV) by real-time RT-PCR. Lett. Appl. Microbiol. 2008, 46, 55-60. [CrossRef] [PubMed]

20. Xiao, X.L.; Wu, H.; Yu, Y.G.; Cheng, B.Z.; Yang, X.G.; Chen, G.; Liu, D.M.; Li, X.F. Rapid detection of a highly virulent Chinese-type isolate of Porcine Reproductive and Respiratory Syndrome virus by real-time reverse transcriptase PCR. J. Virol. Methods 2008, 149, 49-55. [CrossRef] [PubMed]

21. Markoulatos, P.; Siafakas, N.; Moncany, M. Multiplex polymerase chain reaction: A practical approach. J. Clin. Lab. Anal. 2002, 16, 47-51. [CrossRef] [PubMed]

22. Xu, X.G.; Chen, G.D.; Huang, Y.; Ding, L.; Li, Z.C.; Chang, C.D.; Wang, C.Y.; Tong, D.W.; Liu, H.J. Development of multiplex PCR for simultaneous detection of six swine DNA and RNA viruses. J. Virol. Methods 2012, 183, 69-74. [CrossRef] [PubMed] 
23. Liu, J.K.; Wei, C.H.; Yang, X.Y.; Dai, A.L.; Li, X.H. Multiplex PCR for the simultaneous detection of porcine reproductive and respiratory syndrome virus, classical swine fever virus, and porcine circovirus in pigs. Mol. Cell. Probes 2013, 27, 149-152. [CrossRef] [PubMed]

24. Spear, A.; Faaberg, K.S. Development of a genome copy specific RT-qPCR assay for divergent strains of type 2 porcine reproductive and respiratory syndrome virus. J. Virol. Methods 2015, 218, 1-6. [CrossRef] [PubMed]

25. Pileri, E.; Gibert, E.; Martín-Valls, G.E.; Nofrarias, M.; López-Soria, S.; Martín, M.; Díaz, I.; Darwich, L.; Mateu, E. Transmission of Porcine reproductive and respiratory syndrome virus 1 to and from vaccinated pigs in a one-to-one model. Vet. Microbiol. 2017, 201, 18-25. [CrossRef] [PubMed]

26. Charpin, C.; Mahé, S.; Keranflec'h, A.; Belloc, C.; Cariolet, R.; Le Potier, M.F.; Rose, N. Infectiousness of pigs infected by the Porcine Reproductive and Respiratory Syndrome virus (PRRSV) is time-dependent. Vet. Res. 2012, 43, 69. [CrossRef] [PubMed]

27. Pileri, E.; Gibert, E.; Soldevila, F.; García-Saenz, A.; Pujols, J.; Diaz, I.; Darwich, L.; Casal, J.; Martín, M.; Mateu, E. Vaccination with a genotype 1 modified live vaccine against porcine reproductive and respiratory syndrome virus significantly reduces viremia, viral shedding and transmission of the virus in aquasi-natural experimental model. Vet. Microbiol. 2015, 175, 7-16. [CrossRef] [PubMed]

28. Rose, N.; Renson, P.; Andraud, M.; Paboeuf, F.; Le Potier, M.F.; Bourry, O. Porcine reproductive and respiratory syndrome virus (PRRSv) modified-live vaccine reduces virus transmission in experimental conditions. Vaccine 2015, 33, 2493-2499. [CrossRef] [PubMed]

(C) 2017 by the authors. Licensee MDPI, Basel, Switzerland. This article is an open access article distributed under the terms and conditions of the Creative Commons Attribution (CC BY) license (http://creativecommons.org/licenses/by/4.0/). 